\title{
EFFECT OF MELATONIN APPLICATION AROUND IMMEDIATE IMPLANTS
}

\author{
Yasser M Awwad ${ }^{*}$, Mohammed A Khalil ${ }^{* *}$, Salah A Al Sayed ${ }^{* * *}$
}

\begin{abstract}
Background: The aim of the current study was designed to evaluate the clinical and radiographic effects of the melatonin gel around immediately placed dental implants in maxillary anterior teeth. Methods: Fourteen patients were selected from those who attended the outpatient clinics of Oral and Maxillofacial Surgery Department of Al-Azhar University Hospitals. Group A: beta tricalcium phosphate bone graft mixed with melatonin gel was packed around the implant to fill the buccal gap. For Group B: beta tri calcium phosphate bone graft mixed with saline was packed around the implant to fill the buccal gap. PRF membrane is prepared to cover the graft. Results: Implant stability showed increasing value in both groups a higher mean value was recorded in group A. Increased bone density throughout follow-up period.at 3 months follow-up, a higher mean value was recorded in group A, with a significant difference. Conclusion: Melatonin achieve increased bone density and stability in the healing period. Immediate post extraction implant offers patient satisfaction due to less time and less pain.
\end{abstract}

\section{INTRODUCTION}

The potential advantages of the immediate implants are decrease in number of surgical interventions, shortened time of treatment, bone preservation around the socket especially the buccal bone ${ }^{(1-3)}$.

Orientation of dental implants is easier and more ideal, good aesthetics for soft tissue, absence of active infections, Adequate mechanical retention due to intact buccal bone and narrow alveolar bone $(4,5)$. Clinicians have also used other materials and methods to augment edentulous ridges and small bony defects or vertical gap between the bony walls of the socket and the cervical part of the implant especially in upper anterior region owing to conical shape of the socket.

Melatonin is chemically recognized as N-acetyl5-methoxytryptamine. It is a compound occurring naturally in plants, microbes and animals. Melatonin called hormone of night is secreted by the pineal gland, and its plasma levels concentration are 50 folds higher in night in comparison to daytime. A variety of peripheral cells play a role in production of melatonin such as epithelial cells, bone marrow cells, and lymphocytes ${ }^{(6)}$. Though melatonin is a hormone, it does not act on a specific organ, it has several functions; stimulation of the synthesis of type I collagen fibers, regulation of the body temperature, sexual development, antioxidant scavenging and detoxifying free radicals thus inhibiting the process of bone resorption through interfering with the function of osteoclasts ${ }^{(7)}$.

Melatonin has been investigated relative to bone remolding osteoporosis, osseointegration of dental implants and dentine formation It is hypothesized that melatonin, perhaps through three principle actions, modulates bone metabolism. Firstly, melatonin directly affects the actions of osteoblast and osteoclast ${ }^{(8,9)}$.

Numerous studies documented that melatonin increases pre-osteoblast/osteoblast/osteoblastlike cell proliferation, promotes the expression of type I collagen and bone marker proteins (e.g., alkaline phosphatase, osteopontin, bone sialoprotein

* BDS, Faculty of Dental Medicine, Cairo University.

** Professor, Department of Oral and Maxillofacial Surgery, Faculty of Dental Medicine, Al-Azhar University (Boys) Cairo *** Lecturer, Department of Oral and Maxillofacial Surgery, Faculty of Dental Medicine, Al-Azhar University (Boys) Cairo 
and osteocalcin), and stimulates the formation of a mineralized matrix in these cells ${ }^{(10-14)}$. Besides, melatonin inhibits the differentiation of osteoclasts via decreases in the expression of RANK mRNA and increases in both the mRNA and protein levels of osteo-protegerin ${ }^{(15,16)}$. Secondly, melatonin indirectly regulates bone metabolism through the interaction with systemic hormones (e.g., PTH, calcitonin, and estrogen) or other molecules. This study aims to assess melatonin application around immediate dental implant to improve bone synthesis and ensure better results.

\section{PATIENTS AND METHODS}

Fourteen patients with teeth indicated for extraction in aesthetic zone were selected from those who attended the outpatient clinics of Oral and Maxillofacial Surgery Department of Al-Azhar University Hospitals. Patients were divided into two groups: Group A (beta-tri calcium phosphate mixed with melatonin gel was applied into the buccal jumping gap), Group B (The beta tri calcium phosphate mixed with saline was applied into the gap around the immediately placed dental implant).

\section{Preoperative preparation:}

All patients were prepared for surgery by the same protocol as follow:

1. Preoperative photographs.

2. Preoperative radiographs. (periapical, and cone beam computed tomography (CBCT).

\section{Operative procedures}

Injectable Local anesthesia. (infiltration technique) for anaesthetizing of the site of surgery had been given to the patient. Full thickness mucoperiosteal flap was then reflected Started with small elevator in the interproximal area mesial and distal between the tooth and the interdenal bone to allow luxation of the tooth by cutting the periodontal ligaments interproximaly. After the tooth has been started to luxate, we used either remaining root forceps or large size tissue forceps in up and down motion (i.e. push and pull) the socket was cleaned and irrigated with normal saline to flush any debris from the socket. The socket has been curated by bone curate as it is mandatory procedures for any immediate implant case to remove the remnant of periodontal ligament and any granulation or fibrous tissue inside the socket. Drilling has been extended $2-3 \mathrm{~mm}$ apically beyond the apex of the root or the base of the socket to gain primary stability for the implant from the apical bone. Implant was installed in the prepared socket

For Group A: beta tri-calcium phosphate bone graft mixed with melatonin gel was packed around the implant to fill the buccal gap. For Group B: beta tri calcium phosphate bone graft mixed with saline was packed around the implant to fill the buccal gap. PRF membrane is prepared to cover the graft. Flap repositioned and sutured.

\section{Post-operative evaluation}

\section{A- Clinically}

Stability

Probing depth

\section{B-Radiographically (CBCT)}

Bone density

Crestal bone loss

\section{RESULTS}

The present study was done to evaluate the effect of melatonin gel when used with immediate implant in upper anterior region. Fourteen implants were placed into fourteen patients each patient receives one implant. The patients were divided into 2 groups: Group A beta tri calcium phosphate bone substitute mixed with melatonin gel. Group B beta tri calcium phosphate bone substitute mixed with saline. All implants were placed into maxilla. Follow-up for bone density, crestal bone loss, probing depth and stability. 


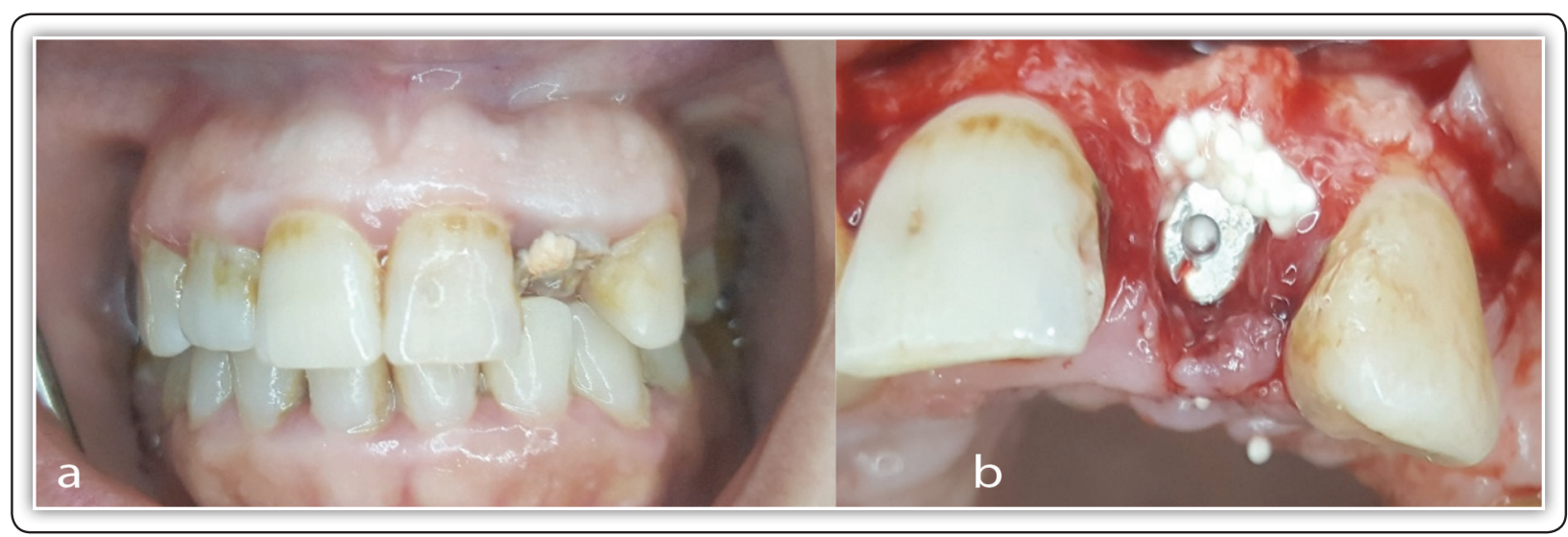

FIG (1) Aspire-operative photo showing non-restorable upper left lateral toot $b$, graft condensed into the buccal gap between implant and buccal bone

TABLE (1) Comparison between the two studied groups according to different parameters

\begin{tabular}{|c|c|c|c|c|}
\hline & Group A & Group B & $\begin{array}{l}\text { Test of } \\
\text { Sig. }\end{array}$ & $\mathrm{p}$ \\
\hline \multicolumn{5}{|l|}{ Gender } \\
\hline Male & $4(57 \%)$ & $3(43 \%)$ & \multirow{2}{*}{$\begin{array}{l}\chi^{2}= \\
0.4\end{array}$} & \multirow{2}{*}{0.527} \\
\hline Female & $3(43 \%)$ & $4(57 \%)$ & & \\
\hline Age & $35.4 \pm 3.07$ & $36.6 \pm 3.7$ & $\mathrm{t}=0.1314$ & 0.899 \\
\hline \multicolumn{5}{|c|}{ Implant stability (ISQ units) } \\
\hline At surgery & $47.42^{c} \pm 4.34$ & $47.28^{c} \pm 5.23$ & $\mathrm{t}=0.017$ & 0.98 \\
\hline 3 months & $60^{\mathrm{b}} \pm 4.61$ & $54.7^{b} \pm 4.02$ & $\mathrm{t}=2.29^{*}$ & $0.041^{*}$ \\
\hline 6 months & $77.7^{\mathrm{a}} \pm 10.3$ & $70.8^{\mathrm{a}} \pm 12.68$ & $\mathrm{t}=1.12$ & 0.286 \\
\hline \multicolumn{5}{|c|}{ Probing depth $(\mathrm{mm})$} \\
\hline 2 weeks & $1.54 \pm 0.32$ & $1.6 \pm 0.3$ & $\mathrm{t}=0.36$ & 0.72 \\
\hline 3 months & $1.55 \pm 0.4$ & $1.61 \pm 0.38$ & $\mathrm{t}=0.29$ & 0.78 \\
\hline 6 months & $1.64 \pm 0.37$ & $1.7 \pm 0.45$ & $\mathrm{t}=0.27$ & 0.79 \\
\hline \multicolumn{5}{|l|}{ Bone density } \\
\hline 1st week & $972 \mathrm{c} \pm 74.1$ & $971.4 \mathrm{c} \pm 81.7$ & $\mathrm{t}=0.014$ & 0.99 \\
\hline 3 months & $1093.63 b \pm 69.4$ & $1006.71 \mathrm{~b} \pm 63.2$ & $\mathrm{t}=2.45^{*}$ & $0.031^{*}$ \\
\hline 6 months & $1158.28 \mathrm{a} \pm 67.8$ & $1081.7 \mathrm{a} \pm 71.5$ & $t=2.06$ & 0.0622 \\
\hline \multicolumn{5}{|c|}{ Crestal bone loss (mm) } \\
\hline After 1 week & $0 \mathrm{~b} \pm 0$ & $0 \mathrm{~b} \pm 0$ & $\mathrm{t}=0$ & 1 \\
\hline 3 months & $0.38 \mathrm{a} \pm 0.1$ & $0.4 \mathrm{a} \pm 0.12$ & $\mathrm{t}=0.34$ & 0.74 \\
\hline 6 months & $0.41 \mathrm{a} \pm 0.12$ & $0.43 \mathrm{a} \pm 0.13$ & $\mathrm{t}=0.014$ & 0.99 \\
\hline
\end{tabular}

$c^{2}$ : Chi square test

t: Student t-test

$p: p$ value for comparing between the two studied groups

Means in the column with common letters are not significant for comparing between different periods

*: Statistically significant at $p \leq 0.05$

\section{DISCUSSION}

In this study, Osstell Mentor was used for recording Implant Stability Quotient (ISQ) measurement at the time of implant placement and after 3, 6 months in both groups. The higher the ISQ value, the more stable the implant ${ }^{(17,18)}$. Many studies have shown that implants whose ISQ values exceed 65 before functional loading have $99 \%$ survival rate and ISQ values of 57 to 82 have been used as threshold values for implant success ${ }^{(19)}$. ISQ values less than 45 indicate failure of the implant. The current study has indicated successful implants for all patients throughout this study. The ISQ values recorded in this study at time of surgery, revealed almost similar mean value (Group A 47.42 \pm 4.34 , Group B 47.28 \pm 5.23 ) with no statistically significant difference, After 3 months, a higher mean value was recorded in

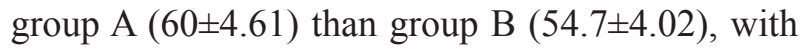
a significant difference $(\mathrm{p}=0.041)$, At 6 months, a higher mean value was recorded in group A, with no significant difference

Probing depth when comparing both groups at two weeks, revealed a higher mean value in group B, with no statistically significant difference $(\mathrm{p}=0.72)$. At 3 months, a higher mean value was recorded in group $B$, with no significant difference $(p=0.78)$. At 6 months, a higher mean value was recorded in 
group B, with no significant difference $(\mathrm{p}=0.79)$. Pre-implant crestal bone level was evaluated on the mesial and distal surface of implant using (CBCT) at 3 and 6 months after the operation by using the measuring tools on CBCT system. Reference points for the linear measurements were the most coronal margin of the implant collar in relation to the most coronal point of bone -to- implant contact. Descriptive statistics of crestal bone loss results expressed in (mm). Comparing both groups after 1 week, revealed a value of $0 \pm 0$ in both groups, with no statistically significant difference $(p=1)$. At 3 months, a higher mean value was recorded in group $\mathrm{B}$, with no significant difference $(\mathrm{p}=0.74)$. At 6 months, a higher mean value was recorded in group $B$, with no significant difference $(p=0.99)$ Studying the effect on time in group A revealed a statistically significant gradual increase in the mean value to reach its highest level at 6 months $(p<0.0001)$. Studying the effect on time in group B revealed a statistically significant gradual increase in the mean value to reach its highest level at 6 months $(\mathrm{p}<0.0001)$

Numerous studies have shown that bone resorption around the implant neck does not start until the implant is uncovered and exposed to the oral cavity. This invariably leads to bacterial contamination of the gap between the implant and the superstructure. Bone remodeling will progress until the biological width has been created and stabilized. This width progresses not only apically along the vertical axis, but also 1 to $1.5 \mathrm{~mm}$ horizontally, according to studies conducted by Tarnow et al ${ }^{(20)}$. Esposito et al ${ }^{(21)}$. This is the reason for maintaining a minimum distance of $3 \mathrm{~mm}$ between two implants and platform switching in the aesthetic reconstruction zone in order to obtain intact papillae and stable inter-implant bone.

Silva et al ${ }^{(22)}$, concluded that CBCT images is a reliable tool for bone density, so in the current study, CBCT images were used for evaluating presence of radiolucency, bone density around the implant sides all over. The parameters for production of the image were constant for all images. Comparing both groups at one week, revealed almost similar mean value, with no statistically significant difference $(p=0.99)$. At 3 months, a higher mean value was recorded in group $\mathrm{A}$, with a significant difference $(\mathrm{p}=0.031)$. At 6 months, a higher mean value was recorded in group A, with no significant difference $(p=0.062)$, Studying the effect on time in group A revealed a statistically significant gradual increase in the mean value to reach its highest level at 6 months $(p<0.0001)$. Studying the effect on time in group B revealed a statistically significant gradual increase in the mean value to reach its highest level at 6 months $(\mathrm{p}<0.0001)$.

In accordance with Joly et al ${ }^{(23)}$ assessment of bone density was radiographically evaluated which is a non-invasive and fast technique. Increased bone density and stability associated with Melatonin implantation around implant fixtures with significant difference in the 3 months follow-up can be attributed to Kasuhito et al (24) advocations that melatonin showed increase in the activity of alkaline phosphatase (ALP) when applied in osteotomy sites and enhanced mRNA expression of the early phase type I collagen and shortened time of mature osteoblast differentiation. Bone grafting and melatonin are thus considered as bone stimulators through enhancing osteoblastic differentiation, proliferation and potential early matrix production and mineral deposition

\section{REFERENCES}

1. Schulte W, Heimke G. The Tubinger immediate implant. Quintessenz. 1976;27(6):17-23. (in German)

2. Watzek G, Haider R, Mendsdorff-Pouilly N, Haas R., immediate and delayed implantation for complete restoration of the jaw following extraction of all residual teeth: a retrospective study comparing different types of serial immediate implantation. Int J Oral Maxillofac Implants. 1995;10(5):561-7.

3. Van Der Weijden F, Dellacqua F, Slot D. Alveolar bone dimensional changes of post extraction sockets in humans: a systematic review. J Clin Periodontal. 2009;36(12):1048-58. 
4. SCHULTZ A. Guided tissue regeneration (GTR) of nonsubmerged implants in immediate extraction sites. Pract periodontics Aesthet Dent. 1992;12(3);206-17

5. WERBITT M, GOLDBERG P, FULL C. The immediate implant: bone preservation and bone regeneration. Int $\mathrm{J}$ Periodontics Restorative Dent. 1992;12(3):206-17

6. Yamazaki S, Ochi M, Hirose Y, Nakanishi Y, Nakade O. Melatonin enhances peri-implant osteogenesis in the femur of rabbits. J Oromax Biomech 2008; 14: 34-8.

7. Greany J. Using Melatonin to Accelerate Osseointegration. Journal of Pineal Research 2008: 45:174-9.

8. 8. Cutando A., Gomez-Moreno G., Arana C., Acuna-Castroviejo D., Reiter R.J. Melatonin: Potential functions in the oral cavity. J. Periodontol. 2007; 78:1094-1102.

9. Jie L., Hong-yu Z., Wen-Guo F., Wei-Guo D., Shen-Li F., Hong-Wen H., Fang H. Melatonin influences proliferation and differentiation of rat dental papilla cells in vitro and dentine formation in vivo by altering mitochondrial activity. J. Pineal Res. 2013; 54:170-178

10. Roth J.A., Kim B.G., Lin W.L., Cho M.I. Melatonin promotes osteoblast differentiation and bone formation. J. Biol. Chem. 1999; 274:22041-22047.

11. Nakade O., Koyama H., Ariji H., Yajima A., Kaku T. Melatonin stimulates proliferation and type I collagen synthesis in human bone cells in vitro. J. Pineal Res. 1999; 27:106-110.

12. Radio N.M., Doctor J.S., Witt-Enderby P.A. Melatonin enhances alkaline phosphatase activity in differentiating human adult mesenchymal stem cells grown in osteogenic medium via MT2 melatonin receptors and the MEK/ERK (1/2) signaling cascade. J. Pineal Res. 2006; 40:332-342.

13. Satomura K., Tobiume S., Tokuyama R., Yamasaki Y., Kudoh K., Maeda E., Nagayama M. Melatonin at pharmacological doses enhances human osteoblastic differentiation in vitro and promotes mouse cortical bone formation in vivo. J. Pineal Res. 2007; 42:231-239.

14. Sethi S., Radio N.M., Kotlarczyk M.P., Chen C.T., Wei Y.H., Jockers R., Witt-Enderby P.A. Determination of the minimal melatonin exposure required to induce osteoblast differentiation from human mesenchymal stem cells and these effects on downstream signaling pathways. J. Pineal Res. 2010; 49:222-238.
15. Koyama H., Nakade O., Takada Y., Kaku T., Lau K.H. Melatonin at pharmacologic doses increases bone mass by suppressing resorption through down-regulation of the RANKL-mediated osteoclast formation and activation. J. Bone Miner. Res. 2002; 17:1219-1229.

16. Suzuki N., Hattori A. Melatonin suppresses osteoclastic and osteoblastic activities in the scales of goldfish. J. Pineal Res. 2002; 33:253-258.

17. Park JC, Lee JW, Kim SM, Lee JH. Implant Stability Measuring Devices and Randomized Clinical Trial for ISQ Value Change Pattern Measured from Two Different Directions by Magnetic RFA, Rapidly Evolving Practice 2011;5:111-30.

18. Valderrama P, Oates TW, Jones AA, Simpson J, Schoolfield JD, Cochran DL, et al. Evaluation of two different resonance frequency devices to detect implant stability: A clinical trial. J Periodontol 2007; 78:262-72.

19. Bornstein MM, Hart CN, Halbritter SA, Mo rton D, Buser D. Early loading of non-submerged titanium implants with a chemically modified sand-blasted and acid-etched surface: 6-month results of a prospective case series study in the posterior mandible focusing on peri implant crestal bone changes and implant stability quotient (ISQ) values. Clin Implant Dent Relat Res. 2009;11(4):338-47.

20. Tarnow DP, Cho SC, Wallace SS. The effect of inter-implant distance in the height of inter-implant bone crest. J Periodontol 2000;71:546-549

21. Esposito M, Ekestubbe A, Grondahl K. Radiological evaluation of marginal bone loss at tooth surface facing single Branemark implants. Clin Oral Implants Res 1993; 4:151-157

22. Silva I, Freitas D, Ambrosano G, Bóscolo F, Almeida S. Bonedensity: comparative evaluation of Hounsfield units in multislice and cone beam computed tomography. Braz Oral Res. 2012; 26:550-6.

23. Joly J, de Lima A, da Silva R. Clinical and radiographic evaluation of soft and hard tissue changes around implants. Pilot study. J periodontal 2003; 74 (8): 1097-103.

24. Kazuhito S, Satoru T, Reiko T: melatonin at pharmacological doses enhances human osteoblastic differentiation in vitro. J Pineal Res 2008; 44: 387-96. 